\title{
Analysis of Grassland Ecological Compensation in Western Sichuan
}

\author{
Zhang Dawei \\ Southwest Minzu University, Chengdu, Sichuan, China
}

Keywords: western Sichuan grassland ecological compensation; main functional area; development strategy; environmental policy

\begin{abstract}
Based on a comprehensive analysis of the natural, economic, and ecological characteristics of western Sichuan, this paper aims at the main functions of ecologically fragile areas in western Sichuan in Sichuan's socio-economic development, and proposes regional industrial development, population distribution, ecological restoration and protection. Other development strategies, such as building an open ecological protection mechanism, further improving ecological compensation policies, and establishing a green GDP system, have explored supporting environmental policy options, seized the opportunity to seize the new round of large-scale western development, and promoted the coordinated development of Sichuan's regions.
\end{abstract}

\section{Introduction}

Northwestern Sichuan is a typical fragile ecologically fragile region in China. Since the implementation of reform and opening up, especially since the implementation of the Western Development Program, the region's economic and social development has been rapid. The impact on human resources and the ecological environment has gradually expanded, resulting in unbalanced regional development. The ecological environment in northwestern Sichuan is facing widespread vulnerability, partial improvement, and overall deterioration, and the ecological carrying capacity and ecological functions have dropped dramatically.

\section{Main Features of Western Sichuan}

\subsection{Natural environment characteristics}

With an area of about 200,000 square kilometers, Northwestern Sichuan is one of the five largest pastoral areas in China. Yak cows, sheep, and other livestock have the largest population in Sichuan and are the main animal husbandry bases in Sichuan. At the same time, Northwestern Sichuan is also a region rich in resources such as tourism, species, and mineral resources in western China. The area boasts 3 world-famous scenic spots, 2 national scenic spots, 18 provincial scenic spots, and is one of the world's most famous giant panda habitats. It is also a treasure trove of biodiversity in our province.

\subsection{Social and economic development features}

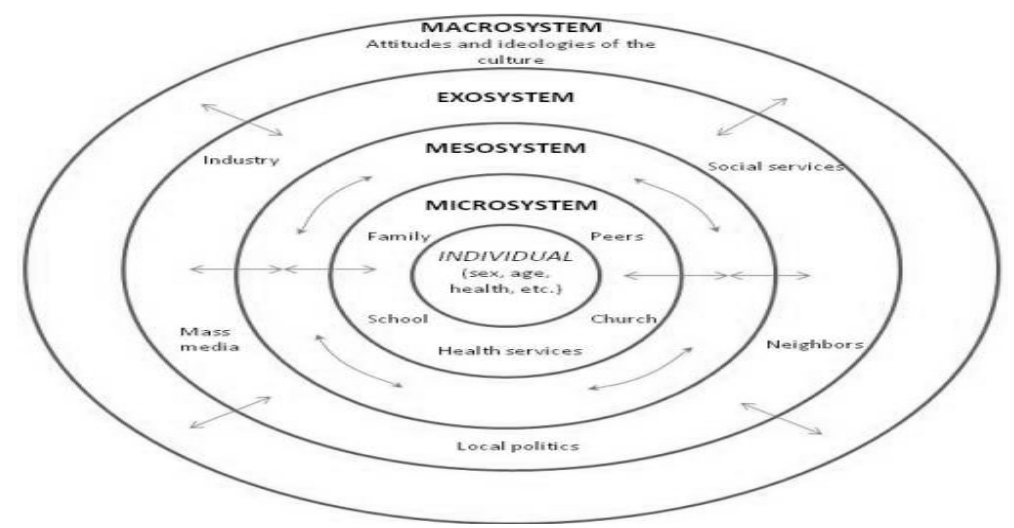

Fig. 1 The status quo of grassland ecology in western Sichuan 
Northwestern Sichuan is an agricultural economic region based on traditional farming and animal husbandry. Population is dispersed, and social development lags behind. $69.2 \%$ of the population in the region is engaged in the primary industry, and animal husbandry is the main pillar industry and the main economic source of farmers and herdsmen. In 2009, the per capita GDP of Aba Prefecture was 12,186 yuan. Compared with the proportion of the three industrial structures in the province, the proportion of the first and third industries is relatively high, and the proportion of the secondary industry is relatively low, indicating that agriculture, animal husbandry and tourism are the most important in the region.

\section{Main Functions and Development Strategy of Ecologically Vulnerable Areas in Western Sichuan}

\subsection{Main function positioning}

According to the characteristics of economic and social development, natural environment and carrying ecological functions in northwestern Sichuan, the region has the following characteristics: (1) The environmental carrying capacity is weak, and the basic conditions for large-scale population agglomeration and industrial development are not available; (2) It is not only a variety of resources The enriched area is also a typical agricultural and pastoral economic area with backward industrial development; (3) The population distribution is decentralized and social development is lagging behind. Based on the improvement of the environment, we will focus on addressing the livelihood issues of farmers and herdsmen, grasp the development of characteristic biological resources, build a world-wide ecological tourism destination.

\subsection{Development strategy}

The proposal of the four major functional areas embodies the concept of space control. The essence of this is the division of policy areas, which embodies the implementation of the scientific concept of development at the spatial level. In order to achieve regional economic and social coordination and sustainable development, it is necessary to adjust and improve regional policies and performance evaluation methods in accordance with the positioning of main functions, so that the entire policy system can be harmonized with regional development strategies. The land policy, population policy, environmental policy, ecological compensation policy, and fiscal policy under the implementation of the main functional area strategy have been discussed.

\subsubsection{Vigorously implement a low-carbon economic strategy and broaden the channels for sustainable development}

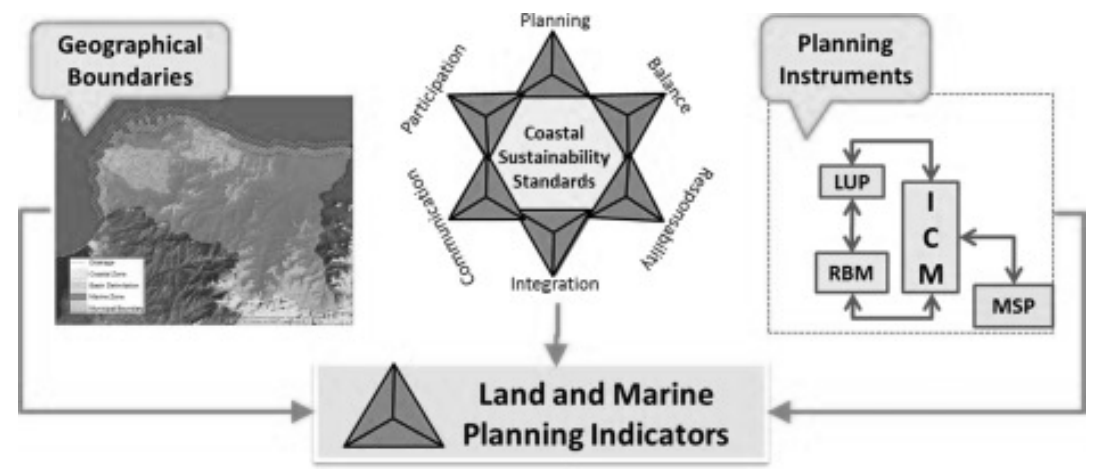

Fig.2 Utilization of grassland resources in western Sichuan

The ecologically fragile areas in northwestern Sichuan Province should rationally develop the primary and tertiary industries that are less destructive to the ecological environment, and gradually reduce the proportion of secondary industries. For example, the proportion of secondary industries in Aba Prefecture to GDP has decreased from 43.2\% in 2007 to 2009. 39.4\%. First, efforts should be made to improve the development level of agriculture and animal husbandry, speed up the construction of low-carbon pastoral areas, and develop ecological agriculture and animal husbandry. 
In combination with herdsmen's settlement plan and new life in tents implemented in Sichuan Province, we will guide farmers and herders to change their grazing methods and establish grazing methods for settlement or semi-domestic settlement.

\subsubsection{Promote the orderly shift of the population and form a rational layout}

First, according to the restrictions on the restriction of development zones and the ban on development zones, the orderly transfer of peasants and herdsmen in the core area of the banned development zone should be gradually promoted. Through appropriate incentive policies, the peasants and herdsmen living in national nature reserves and their core areas are gradually transferred to the outside. The second is to actively promote herdsmen settlement action plan and ecological resettlement project, and strive to improve people's livelihood. Third, we must vigorously promote population gradient transfer, gradually promote the transfer of population from ecological core areas to non-core areas, transfer of population from rural and pastoral areas to county towns and market towns, and prohibit the development of regional populations to restrict the development of the development zone, and transfer of county and township populations to the Mainland. Gradient population transfer is an important way to reduce the impact of population on the ecological environment in northwestern Sichuan.

\section{Selections of Environmental Policies for Ecologically Vulnerable Areas in Western Sichuan}

\subsection{Construct an open ecological protection mechanism}

In the process of promoting the protection and restoration of the ecological functions in northwestern Sichuan, an open participatory ecological protection mechanism should be constructed to strengthen the coordination of interests among all sectors of society. It is necessary to increase the financial input of the central and provincial governments. We will strengthen fiscal transfer payments for construction projects in the northwestern Sichuan area, and develop project financing for off-site projects, and gradually enable local residents to enjoy equal access to basic public services in areas such as health care, education, social security, and ecological protection and construction.

\subsection{Further improve the ecological compensation policy}

It is more important to restrict development zones and prohibition of development zones from undertaking ecological protection functions, and economic activities that contradict ecological protection functions will be limited. Therefore, further adjustment and improvement of relevant ecological compensation policies are the key to long-term and stable implementation of the guidelines for ecological environmental protection and construction. Since the large-scale development of the western region, the state has successively issued a series of policies and actively explored ways and measures for the development of ecological compensation in the west. However, it still remains at the policy level and has not yet formed laws and regulations, which has led to a reduction in the importance of ecological compensation in the western region in practical work.

\section{Summary}

At present, with the implementation of the new regional coordinated development strategy, the current environmental policy and the regional economic development policy are still disconnected. The current environmental management system is also not conducive to the implementation of regionally differentiated environmental policies. Mutual complementarities and coordination need to be strengthened. Compensation policies for promoting environmental protection, restoration and construction of the ecological environment are not yet complete. In the area, the cost of planting trees is obviously different. Therefore, the selection of environmental policies in ecologically fragile areas in northwestern Sichuan should focus on the construction of open ecological protection mechanisms and further improvement of ecological compensation policies. 


\section{References}

[1] Dai Q W. Study on the Spatial Selection of Ecological Compensation Objects: A Case Study of Water Conservation of Grasslands in Gannan Tibetan Autonomous Prefecture [J]. Journal of Natural Resources, 2010, 221(2):670-673.

[2] Matthias A, Bernhard S, Martink O, et al. Effects of ecological compensation meadows on arthropod diversity in adjacent intensively managed grassland [J]. Biological Conservation, 2010, 143(3):642-649.

[3] Liu Y, Zhang X. A Study on the Herdsmen's Choice of Grassland Ecological Compensation Mode [J]. Ecological Economy, 2018. 